\title{
Recently Unusual Surgical Educational Case: A Real Giant Nodular Goiter
}

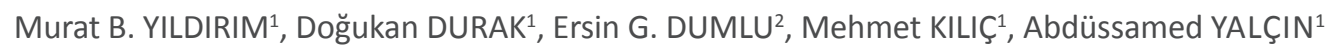

'Departmant of General Surgery, Yıldırım Beyazıt University, Ankara, Turkey

${ }^{2}$ Departmant of General Surgery, Atatürk Education and Research Hospital, Ankara, Turkey

\section{ABSTRACT}

Goitre is a common endocrine abnormality. It is an enlargement of the thyroid gland. If goitre left untreated. they became giant goitre. Giant goitres are becoming increasingly infrequent because of imaging techniques. Although goitre are asymptomatic, they can compress the trachea or oesophagus and cause clinical symptoms such as dyspnea or dysphagia. We present a case of a giant goitre. A 77-year-old woman consulted our clinic. She had the swelling of her neck, had rapidly progressive increase in shortness of breath and had difficulty in swallowing. The huge mass was surgically removed without complications. The pathological result of the patient reported follicular carcinoma of the thyroid/Hurthle cell carcinoma. As such cases have the risk of malignancy, operations must be performed after getting a diagnosis to prevent complicated situations.

Keywords: Giant goitre, Multi-nodular, Thyroid

\section{INTRODUCTION}

Normal thyroid tissue has a homogeneous structure, but sometimes thyroid tissue may show nodule formation. These nodules may occur with follicles junction that is full of colloid or they may occur with less adenoma or cysts. A 5\% nodular goiter incidence is seen at nonendemic regions and 15\% at endemic regions (1). Nodules, which are larger than $1 \mathrm{~cm}$, can only be realized with pal pation at physical examination. Although these nodules are asymptomatic, they may cause symptoms when their sizes become larger. So, for the training purpose, this study aims to study a real huge nodular goiter incidence case that is rarely seen nowadays.

\section{CASE}

A woman patient who was 77 years old and had swelling on her neck for 10 years consulted our hospital clinic at Ankara Atatürk Education and Research Hospital. She had a coronary artery disease and diabetes mellitus disease. The patient had not accepted an operation even if multinodular goiter diagnosis was already made and an operation was offered to her. She reconsulted our clinic because the swelling of her neck had become larger and she had rapidly progressive increase in shortness of breath and had difficulty in swallowing. After her physical examination, bilateral mass lesions were found on her neck region that could be seen with inspection. At palpation, hard mobile mass lesions were seen, which were $10 \mathrm{~cm}$ in diameter, on both sides of the tracheas. When the thyroid function tests of the patient were analyzed, it was seen that the thyroid-stimulating hormone was slightly blunted. At ultrasonography (USG) of the neck, bilateral thyroid gland and isthmus had noticeable heterogeneous appearance, the big one, which was $46.5 \mathrm{~mm}$, was seen at the isthmus localization. As a consequence of the fine-needle aspiration biopsy, which was done along with USG, it was thought 
that the thyroid gland of the patient, which was evaluated as a nondiagnostic nodule, was showing retrosternal extension, so the patient had a computed tomography (CT) scan of her neck done. At CT, the thyroid nodules, which blunted the trachea from the left anterior slightly and showed retrosternal extension, were realized at both the thyroid lobes. The biggest ones measured 76 $x 80 \mathrm{~mm}$ on the left and $48 \times 55 \mathrm{~mm}$ on the right.

Besides, at thyroid scintigraphy, symptoms matching with extensive hyperplastic thyroid gland were seen. Thereupon, with huge multinodular goiter diagnosis, elective operation decision was taken and bilateral total thyroidectomy was performed on the patient, who had pressure complaint. Thereafter, no postoperative development of the complication was observed, and the patient was well, could breathe well, and had no voice problem. She was discharged from the hospital on the second day. There were no problems at follow-ups and controls of the patient after discharge.

The pathological result of the patient reported that both the left lobe $(8 \mathrm{~cm})$ and the right lobe $(3 \mathrm{~cm})$ had follicular carcinoma of the thyroid/Hurthle cell carcinoma. Radioactive iodine treatment was suggested by the council, which was attended by an endocrine nuclear medical specialist.

\section{DISCUSSION}

Multinodular goiter is a frequent disease in society. It is reported that the frequency of the disease is up to $15 \%$ at endemic regions (1). Multinodular goiters may reach large sizes at endemic regions. As multinodular goiter can be asymptomatic, it can show symptoms of hyperthyroidism or hypothyroidism depending on the dysfunction of the thyroid gland (2). Another symptom of multinodular goiter is generating a pressure symptom as a result of the thyroid gland growth. Especially at a retrosternal thyroid, respiratory distress occurs as a result of pressure on the trachea and swallowing difficulty as a result of pressure on the esophagus (3). Goiters, which cause pressure symptoms, can be generally seen with inspection (4). In the present-study case, a huge nodular goiter of the patient was easily seen (Figure 1). As substernal goiter enlarges slowly, it occurs at the sixth decade or in later age groups (5). The patient in the present case took

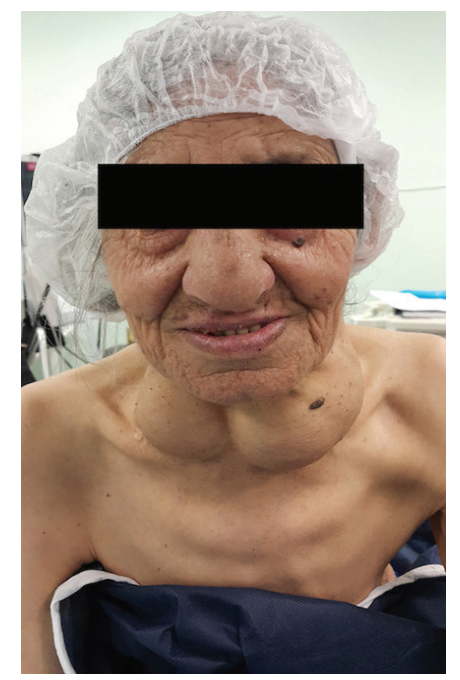

FIgURE 1: Preoperative patient's view.

diagnosis at the age of 67, but pressure symptoms developed in the last 3 months. Tracheal pressure symptoms are seen when the tracheal diameter goes down to below $8 \mathrm{~mm}$. Generally, it shows itself with zonesthesia (6). As a result of pressure on the esophagus, swallowing difficulty and dysphagia develop, but it is rarely seen because it is at esophagus posterior. The patient in the present study had swallowing difficulty before she had respiratory distress. A CT of the neck must be taken for patients who have retrosternal thyroid to reveal the thyroid size and its relation with other organs (7). It was identified that the patient in this study had nodular goiter showing retrosternal extension and blunting trachea from the left anterior slightly as a result of CT. The main indications for thyroidectomy were suspect of malignancy, pressure symptom, and cosmetic concern (8). If the goiter that creates pressure symptoms is cervical or substernal, surgery is indicated. Pressure symptoms are generally seen on substernal goiters (9). If there are no pressure symptoms, then surgical intervention for the substernal goiter becomes obvious $(10,11)$. Because, even if substernal huge goiters are asymptomatic, they can cause sudden respiratory distress in the event of sudden bleeding into nodule or infection. In the present case, because it was symptomatic and showed retrosternal extension, an operation was carried out and bilateral total thyroidectomy was performed. A major part of the substernal huge goiter can be taken out with cervical incision, sometimes sternotomy is also required $(12,13)$. In the present 
case, thyroidectomy was completed with Kocher's incision of 10 $\mathrm{cm}$ without any problem. However, it should be kept in mind that there is a probability of occurrence $(2-5 \%)$ of malignancy $(4,14)$. As a result of pathological examination, it was reported that nodules on both the thyroid lobes were follicular carcinoma of the thyroid and Hurthle cell carcinoma.

As imaging methods are developed at the present time, pathologies of thyroid are identified at an early stage. But goiter cases having pressure symptoms are rarely encountered. As such cases have the risk of malignancy, operations must be performed after getting a diagnosis to prevent complicated situations.

\section{REFERENCES}

1. Hegedus L, Bonnema SJ, Bennedbaek FN. Management of simple nodular goiter: current status and future perspectives. Endocr Rev 2003; 24: 102-32.

2. Laroche CM, Cairns T, Moxham J, Green M. Hypothyroidism presenting with respiratory muscle weakness. Am Rev Respir Dis 1988; $138: 472$

3. Ben Nun A, Soudack M, Best LA. Retrosternal thyroid goiter: 15 years experience. Isr Med Assoc J 2006;8:106-9.
4. Katlic MR, Grillo HC, Wang CA. Substernal goiter. Analysis of 80 patients from Massachusetts General Hospital. Am J Surg 1985; 149:283.

5. Allo MD, Thompson NW. Rationale for the operative management of substernal goiters. Surgery 1983; 94:969.

6. Al-Bazzaz F, Grillo H, Kazemi H. Response to exercise in upper airway obstruction.Am Rev Respir Dis 1975; 111:631.

7. Jennings A. Evaluation of substernal goiters using computed tomography and MR imaging. Endocrinol Metab Clin North Am 2001; 30:401.

8. Singh B, Lucente FE, Shaha AR. Substernal goiter: a clinical review. Am J Otolaryngol 1994;15:409-16.

9. Shaha AR, Burnett $C$, Alfonso $A$, et al. Goiters and airway problems. Am J Surg 1989;158:378-80; discussion 380-1

10. Mack E. Management of patients with substernal goiters. Surg Clin North Am 1995;75:377-94.

11. Allo MD, Thompson NW. Rationale for the operative management of substernal goiters. Surgery 1983;94:969-77.

12. Hedayati N, McHenry CR. The clinical presentation and operative management of nodular and diffuse substernal thyroid disease. Am Surg 2002;68:245-51.

13. White ML, Doherty GM, Gauger PG. Evidence-based surgical management of substernal goiter. World J Surg 2008;32:1285300.

14. Lawson W, Reino AJ, Biller HF. Management of substernal thyroid disease. In: Falk AS (ed). Thyroid Disease Endocrinology, Surgery, Nuclear Medicine and Radiotherapy. 2nd ed. Philadelphia: Lippin- cott-Raven Publishers, pp 447-56, 1997. 